\title{
Mortality Predictive Factors in Subjects With COPD After a Pulmonary Rehabilitation Program: A 3-Year Study
}

\author{
Cátia Saraiva MD, Tiago Abreu MD, Djamila Neves MD, and Fátima Rodrigues MD MSc
}

\begin{abstract}
BACKGROUND: COPD is a high-mortality disease and projected to become the third leading cause of death worldwide by 2030 . Our aim was to evaluate predictors of 3-y mortality and factors associated with early $(1 \mathrm{y})$ and late (second and third year) mortality in subjects with severe COPD who completed a pulmonary rehabilitation program. METHODS: A historical cohort study was performed with subjects with COPD who were admitted to a day-hospital for chronic respiratory failure for a pulmonary rehabilitation program, from January 2008 to December 2010. The population was characterized based on sociodemographic factors, body mass index, smoking habits, lung function tests, respiratory failure, comorbidities, bacterial colonization, Modified Medical Research Council dyspnea index, 6-min walk test, mechanical ventilation, noninvasive ventilation, long-term oxygen therapy, hospital admissions, and mortality. RESULTS: From 183 patients who completed a pulmonary rehabilitation program, 93 had COPD. Our cohort had 78 male and 15 female subjects. The mean age \pm SD was $68.6 \pm 8.9 \mathrm{y}$, ranging from 43 to $85 \mathrm{y}$. After the pulmonary rehabilitation program, there were fewer, although not statistically significantly different hospital admissions $(2.1$ vs $1.7, P=.17)$. Three years after the pulmonary rehabilitation program, 34 subjects died (36.6\%). Hypercapnic respiratory failure $(P=.02)$, noninvasive ventilation $(P=.002)$, lung cancer $(P=.001)$, shorter 6-min walk distance $(P=.03)$, and higher number of previous hospital admissions $(P<.001)$ were associated with a higher mortality rate. CONCLUSION: There is a high mortality rate in late-stage patients with COPD. The most relevant factors associated with mortality were lung cancer, respiratory failure and noninvasive ventilation, severe exacerbations with hospitalization, and lower functional exercise capacity. Key words: COPD; pulmonary rehabilitation; mortality; functional exercise capacity; lung cancer; respiratory failure; noninvasive ventilation; exacerbations. [Respir Care 2016;61(9):1179-1185. () 2016 Daedalus Enterprises]
\end{abstract}

\section{Introduction}

COPD is a high-mortality disease, with approximately 2.75 million deaths/y, or $4.8 \%$ of all deaths. ${ }^{1}$ It is projected

\footnotetext{
Drs Saraiva and Neves are affiliated with the Department of Pulmonology, Hospital de Faro, Centro Hospitalar do Algarve, Faro, Portugal. Drs Abreu and Rodrigues are affiliated with the Unidade de Reabilitação Respiratória, Serviço de Pneumologia II, CHLN-Hospital Pulido Valente, Lisbon, Portugal. Dr Rodrigues is also affiliated with NOVA Medical School, Faculdade de Ciências Médicas, Universidade Nova de Lisboa, Lisbon, Portugal.
}

The authors have disclosed no conflicts of interest.

Dr Saraiva presented a version of this work at the European Respiratory Society International Congress, held September 6-10, 2014, in Munich, Germany. to become the third most common cause of death worldwide by the year $2030 .^{2}$ In fact, in 2011, COPD was already the third major cause of death in developed countries, such as the United States. ${ }^{3}$

COPD patients usually have respiratory symptoms, such as dyspnea, chronic cough, or sputum production,, 45 but also present with systemic manifestations of disease, including exercise limitation, ${ }^{6}$ peripheral muscle impairment, ${ }^{6,7}$ secondary pulmonary hypertension, ${ }^{8}$ anemia, ${ }^{9}$

\footnotetext{
Correspondence: Cátia Saraiva MD, Hospital de Faro, Centro Hospitalar do Algarve, Rua Leão Penedo, 8000-386 Faro, Portugal. E-mail: catia_sss@msn.com.
}

DOI: $10.4187 /$ respcare.04477 


\section{Predictive Factors for Mortality in COPD}

malnutrition, ${ }^{10}$ and exacerbations leading to hospital admissions ${ }^{11}$ and mortality. ${ }^{12}$

Pulmonary rehabilitation is, after smoking cessation, undoubtedly one of the most important multidisciplinary global intervention therapies, not only in the management of respiratory symptoms ${ }^{13}$ and decreasing dyspnea, ${ }^{14}$ but also in improving health status ${ }^{13,15}$ and exercise capacity, ${ }^{16}$ ameliorating psychosocial dysfunction, ${ }^{13}$ and reducing health-care resource utilization, ${ }^{17,18}$ namely reducing hospital readmissions and mortality among patients who received pulmonary rehabilitation after an exacerbation of COPD. ${ }^{19,20}$

It is recognized that individuals with COPD who have low levels of daily physical activity have higher mortality rates compared with those who are more physically active. ${ }^{21}$ Therefore, a pulmonary rehabilitation program assumes a fundamental role in the prognosis of these patients. The long-term survival of patients with chronic respiratory disease who are referred for pulmonary rehabilitation, however, is generally poor, not only because of severely advanced respiratory disease and the negative impact of exacerbations, but also due to the burden of comorbidities. 6,16

Based on these associations, we designed a study to determine predictors of 3-y mortality in advanced stage COPD subjects who have completed a pulmonary rehabilitation program in a day-hospital for chronic respiratory failure. We also investigated factors associated with early (1 y) and late mortality (second and third year) and with fewer hospital admissions after the program.

\section{Methods}

We performed an historical cohort study of baseline characteristics in subjects who completed a pulmonary rehabilitation program in our day-hospital for chronic respiratory failure, from January 2008 to December 2010.

Inclusion criteria were: diagnosis of COPD according to the Global Initiative for Chronic Obstructive Lung Disease (GOLD) criteria ${ }^{4}$ of $\mathrm{FEV}_{1} / \mathrm{FVC}$ after bronchodilator of $<0.70$ and completion of a pulmonary rehabilitation program.

The pulmonary rehabilitation program had a length of 12-16 weeks and included aerobic exercise training on a treadmill or a cycle ergometer with a target intensity of at least $60 \%$ of the initial incremental exercise test, large body muscle strength training, breathing exercises (including breathing control and airway clearance techniques), psychosocial and nutritional support when required, and an individualized or group self-management educational program. These sessions included education on the correct use of respiratory medication and the importance of regular physical activity and smoking cessation as well as identification of symptoms and signs of exacerbation.

\section{QUICK LOOK}

\section{Current knowledge}

COPD is a high-mortality disease with clinical manifestations including not only respiratory symptoms but also systemic manifestations, such as exercise limitation, peripheral muscle impairment, secondary pulmonary hypertension, anemia, malnutrition, and exacerbations leading to hospital admissions. Pulmonary rehabilitation is one of the most important multidisciplinary therapies. Patients with COPD and low levels of daily physical activity have higher mortality rates compared with patients who are more physically active, but clinical studies have not identified mortality predictive factors in patients with severe COPD after pulmonary rehabilitation.

\section{What this paper contributes to our knowledge}

The most relevant factors associated with mortality found in our study were: lung cancer, respiratory failure and noninvasive ventilation, atrial fibrillation, severe exacerbations with hospitalization, and lower functional exercise capacity. Severe exacerbations predicted mortality. Reducing hospitalizations and improving daily physical activities should be primary goals in the management and treatment of patients with COPD. Thus pulmonary rehabilitation, by enabling these outcomes, becomes a fundamental multidisciplinary intervention therapy that should be promptly offered to these patients.

Subjects were also encouraged to apply a home-exercise routine (stationary cycle at home or regular walking, $30 \mathrm{~min} /$ day, most days of the week) as a way to enhance activity levels and improve activity of daily living efficacy during and beyond the pulmonary rehabilitation program. Regular medical and physiotherapist follow-up was set to monitor clinical status and the maintenance of physically active habits.

The population was characterized by sociodemographic factors: sex, age, working status (active or retired), socioeconomic status (economic insufficiency), and cohabitation (living alone or with cohabitants or institutionalized patients). The population was also characterized according to body mass index, smoking habits, lung function tests (FVC, $\mathrm{FEV}_{1}, \mathrm{FEV}_{1} / \mathrm{FVC}$, total lung capacity, residual volume, lung diffusing capacity determined by the singlebreath technique - carbon monoxide transfer coefficient, respiratory failure, comorbidities, bacterial colonization, Modified Medical Research Council dyspnea index, functional exercise capacity (6-min walk distance), ${ }^{22}$ use of noninvasive ventilation, long-term oxygen therapy, hospital admissions due to COPD exacerbations 3 y before and 


\section{Predictive Factors for Mortality in COPD}

after the pulmonary rehabilitation program, history of mechanical ventilation, and mortality. All subjects' clinical data were collected from the medical records.

An exploratory analysis was carried out for all variables. Categorical data were presented as frequencies (percentages), and continuous variables were presented as mean $\pm \mathrm{SD}$ or median (interquartile range), as appropriate.

We analyzed factors associated with early (1-y) and late (second and third year) all-cause mortality. As a secondary end point, we also looked for factors associated with fewer hospital admissions for COPD exacerbation in the $3 \mathrm{y}$ after completing the pulmonary rehabilitation program.

Inter- and intragroup comparisons were completed using paired $t$ test for continuous variables and Pearson chisquare and analysis of variance tests for categorical variables. Explanatory variables were assessed using binomial logistic regression. $P<.05$ was deemed significant. All data were analyzed using SPSS Statistics version 20.0 for Windows (IBM, Armonk, New York).

Regarding sample size, several factors were considered. Data regarding mortality in COPD are scarce and highly dependent on subjects' characteristics (age and smoking habits) and disease severity ( $\mathrm{FEV}_{1}$, diffusing capacity of the lung for carbon monoxide, dyspnea, the presence and number of exacerbations, comorbidities, $\mathrm{Pa}_{\mathrm{CO}}$, and follow-up time); in general COPD subjects, each of these factors have their own relative risk/hazard ratio, as described, for example, by Nishimura et $\mathrm{al}^{23}$; mortality data regarding patients with severe COPD undergoing pulmonary rehabilitation programs are nonexistent.

Given these conditions, this study ideal (or minimum) sample size is dependent on the tested variable and impossible to present as a single value. As an example, a number based on an extrapolation from data of mortality/survival and hazard ratio defined for each of the above variables in a general COPD cohort is different in several studies. ${ }^{23,24}$

Assuming a type-1 error of $0.05(\alpha)$, a power of $80 \%$, and an expected $40 \%$ mortality rate in our cohort at $3 \mathrm{y}$, the number of subjects $(N)$ to be enrolled should be between 354 (for a variable with a relative risk of 1.4) and 48 (for a variable with a relative risk of 2.6), as computed for dichotomous variables in PS software 3.0 (Vanderbilt University, Nashville, Tennessee). The hospital's ethics committee and administration board approved the trial conduction (institutional review board approval DIRCLIN-22DEZ2014-0430).

\section{Results}

Throughout this period, 183 patients were referred to our unit and completed at least 20 sessions of a pulmo- nary rehabilitation program. Of this group, 93 subjects had COPD and were included in our study: 37 subjects in 2008, 29 subjects in 2009, and 27 subjects in 2010.

Sociodemographic, clinical, and functional characteristics of the subjects are reported in Tables 1 and 2. The vast majority of our subjects were male $(n=78 ; 83.9 \%)$, with a mean age of $68.6 \pm 8.9 \mathrm{y}$ (range $43-85 \mathrm{y}$ ) and a mean body mass index of $25.7 \pm 5.8 \mathrm{~kg} / \mathrm{m}^{2}$ (range 14.0-49.3). Most of our subjects were smokers or former smokers $(97.8 \%)$ with a mean of $59.9 \pm 30.0$ pack-years. When considering economic status, 21 subjects (22.6\%) presented with economic insufficiency. Regarding bacterial colonization, 20 subjects (21.8\%) were colonized with multidrug-resistant bacteria.

The mean $\mathrm{FEV}_{1}$ was $37.1 \pm 13.7 \%$ (range 9-78\%), and mean diffusing capacity (by single-breath technique) was $45.6 \pm 21.4 \%$ (range 18-108\%). Mean functional capacity (6-min walk distance [6MWD]) was $227.7 \pm 91.5 \mathrm{~m}$ (range 30-430).

When considering comorbidities, the mean number was $4.98 \pm 2.19$ (range $0-10$ )/subject. The most frequent comorbidities were cardiovascular: 50 subjects $(53.8 \%)$ had arterial hypertension, and 41 subjects $(44.1 \%)$ had congestive heart failure. The third most frequent comorbidity was bronchiectasis in 45 subjects (48.4\%) (Fig. 1).

During the first year after the pulmonary rehabilitation program, 16 subjects died, corresponding to an early mortality of $17.2 \%$. During the second year, 6 subjects $(6.45 \%)$ died, and 12 subjects (12.9\%) died during the third year, corresponding to a global (3-y) mortality of 34 subjects $(36.6 \%)$.

Throughout the 3-y period and analyzing the subjects' baseline characteristics, hypercapnic respiratory failure $(P=.02)$, noninvasive ventilation $(P=.002)$, lung cancer $(P=.001)$, shorter 6MWD $(P=.027)$, and higher number of previous hospital admissions $(P<.001)$ were all associated with a higher 3-y mortality rate (see Tables 1 and 2). When comparing early versus late mortality, the only factor associated with early mortality was atrial fibrillation, although the association was not statistically significant $(P=.050)$. The number of comorbidities was not statistically different between subjects who died and those who were alive 3 y after the pulmonary rehabilitation program $(5.06 \pm 2.09$ versus $4.93 \pm 2.26, P=.79)$. In the 3 -y period after the pulmonary rehabilitation program, there were fewer hospital admissions than in the 3 y before, although the difference was not statistically significant $(1.7 \pm 2.2$ versus $2.1 \pm 2.6, P=.17)$. When performing logistic regression analysis, previous hospital admissions was the only variable associated with an increased death risk (relative risk 1.57 [CI 1.2-2.0], $P=.001$ ). 
Table 1. Sociodemographic and Clinical Characteristics of Subjects With COPD Who Completed a Pulmonary Rehabilitation Program

\begin{tabular}{|c|c|c|c|c|c|}
\hline Characteristics & All Subjects & Alive Subjects & Deceased Subjects & $n$ & $P$ \\
\hline \multicolumn{6}{|l|}{ Sociodemographic } \\
\hline Male/female sex, $n(\%)$ & 78/15 (83.9/16.1) & $48 / 11(52.2 / 12.0)$ & $30 / 4(32.2 / 4.4)$ & 93 & .39 \\
\hline Age, mean \pm SD y & $68.6 \pm 8.9$ & $67 \pm 10$ & $71 \pm 6$ & 93 & .10 \\
\hline $\mathrm{BMI}$, mean $\pm \mathrm{SD} \mathrm{kg} / \mathrm{m}^{2}$ & $25.7 \pm 5.8$ & $25.8 \pm 5.4$ & $25.6 \pm 6.4$ & 91 & .90 \\
\hline \multicolumn{6}{|l|}{ Smoking habits } \\
\hline Smokers, $n(\%)$ & $11(11.8)$ & $55(27)$ & $67(33)$ & 93 & \\
\hline Former smokers, $n(\%)$ & $80(86.0)$ & $12(13.1)$ & $9(9.8)$ & 93 & \\
\hline Never-smokers, $n(\%)$ & $2(2.2)$ & $2(2.3)$ & $1(1.1)$ & 93 & \\
\hline Pack-years, mean $\pm \mathrm{SD}$ & $59.9 \pm 30.0$ & $34 \pm 38.6$ & $51 \pm 58.0$ & 93 & .053 \\
\hline Economic insufficiency, $n(\%)$ & $21(22.6)$ & $1(1.1)$ & $6(6.5)$ & 93 & .15 \\
\hline \multicolumn{6}{|l|}{ Working status, $n(\%)$} \\
\hline Active & $3(3.4)$ & $33(35.9)$ & $48(52.1)$ & 88 & \\
\hline Retired & 85 (96.6) & $3(3.3)$ & $1(1.1)$ & 88 & \\
\hline \multicolumn{6}{|l|}{ Cohabitation, $n(\%)$} \\
\hline Alone & $7(7.6)$ & & & 92 & \\
\hline Cohabitants & $81(88.0)$ & & & 92 & \\
\hline Institutionalized & $4(4.4)$ & & & 92 & \\
\hline \multicolumn{6}{|l|}{ Clinical characteristics } \\
\hline \multicolumn{6}{|l|}{ Comorbidities, $n(\%)$} \\
\hline Arterial hypertension & $50(53.8)$ & $34(37.0)$ & $16(17.4)$ & 93 & .33 \\
\hline Cardiac failure & $41(44.1)$ & $27(29.4)$ & $13(14.1)$ & 93 & .67 \\
\hline Cor pulmonale & $19(20.4)$ & $13(14.1)$ & $6(6.5)$ & 93 & .61 \\
\hline Atrial fibrillation & $18(19.4)$ & $12(13.0)$ & $6(6.5)$ & 93 & .75 \\
\hline Diabetes mellitus & $15(16.1)$ & $9(9.8)$ & $6(6.5)$ & 93 & .76 \\
\hline OSA & $17(18.3)$ & $10(10.9)$ & $7(7.6)$ & 93 & .66 \\
\hline TB sequelae & $25(26.9)$ & $17(18.5)$ & $8(8.7)$ & 93 & .66 \\
\hline Bronchiectasis & $45(48.4)$ & $29(31.5)$ & $16(17.4)$ & 93 & .85 \\
\hline Interstitial lung disease & $7(7.5)$ & $5(5.4)$ & $2(2.2)$ & 93 & .65 \\
\hline Neoplasm & $6(6.5)$ & $0(0.0)$ & $6(6.5)$ & 93 & .001 \\
\hline Bacterial colonization & $20(21.8)$ & $10(10.9)$ & $10(10.9)$ & 93 & .10 \\
\hline \multicolumn{6}{|l|}{ Respiratory failure, $n(\%)$} \\
\hline Hypoxemic & $31(33.3)$ & $25(27.2)$ & $6(6.5)$ & 93 & \\
\hline Hypercapnic & $53(57.0)$ & $27(29.4)$ & $26(28.3)$ & 93 & .02 \\
\hline Long-term oxygen therapy, $n(\%)$ & $72(77.4)$ & $45(48.9)$ & $27(29.4)$ & 93 & .73 \\
\hline $\mathrm{NIV}, n(\%)$ & $28(30.1)$ & $11(12.0)$ & $17(18.5)$ & 93 & .002 \\
\hline Previous hospital admissions, median (interquartile range) & $1(0-3)$ & $1(0-2)$ & $3(1-5)$ & 93 & $<.001$ \\
\hline $\begin{array}{l}\mathrm{BMI}=\text { body mass index } \\
\mathrm{OSA}=\text { obstructive sleep apnea } \\
\mathrm{TB}=\text { tuberculosis } \\
\mathrm{NIV}=\text { noninvasive ventilation }\end{array}$ & & & & & \\
\hline
\end{tabular}

\section{Discussion}

In our study, there was a high mortality $(36.6 \%)$ in subjects with COPD in the $3 \mathrm{y}$ after completing a pulmonary rehabilitation program, which might be justified by the severity of air-flow limitation (mean $\mathrm{FEV}_{1}$ of $37.1 \%$ ), with significant dyspnea in daily life activities (median Modified Medical Research Council dyspnea index 3), and by a high rate of respiratory failure $(n=84 ; 90.3 \%)$. Although the number of comorbidities was not associated with mortality, some comorbidities might have contributed to mortality, such as lung cancer and cardiovascular diseases. Sex and age, as well as smoking habits, were not associated with increased mortality, similar to other studies. ${ }^{25,26}$

This study also evidenced that throughout the 3-y period, hypercapnic respiratory failure $(P=.02)$, noninvasive ventilation $(P=.002)$, lung cancer $(P=.001)$, shorter 6MWD $(P=.027)$, and a higher number of admissions were associated with a higher mortality rate $(P<.001)$. The presence of respiratory failure and use of noninvasive ventilation also reflected the severity of the disease.

As demonstrated in previous studies, functional exercise capacity, in particular 6MWD, is a strong predictor of 
Table 2. Functional Characteristics Associated With 3-Year Mortality in Subjects With COPD After a Pulmonary Rehabilitation Program

\begin{tabular}{|c|c|c|c|c|c|}
\hline Functional Characteristics & All Subjects & Alive Subjects & Deceased Subjects & $n$ & $P$ \\
\hline $\mathrm{FEV}_{1}$, mean $\pm \mathrm{SD} \mathrm{L}$ & $0.9 \pm 0.3$ & $1.0 \pm 0.3$ & $0.9 \pm 0.3$ & 89 & .16 \\
\hline $\mathrm{FEV}_{1}$, mean $\pm \mathrm{SD} \%$ & $37.1 \pm 13.7$ & $38 \pm 14$ & $35 \pm 14$ & 93 & .19 \\
\hline $\mathrm{FVC}$, mean $\pm \mathrm{SD} \mathrm{L}$ & $2.2 \pm 0.7$ & $2.3 \pm 0.7$ & $2.0 \pm 0.7$ & 90 & .16 \\
\hline $\mathrm{FVC}$, mean $\pm \mathrm{SD} \%$ & $69.7 \pm 21.9$ & $71 \pm 21$ & $67 \pm 23$ & 92 & .49 \\
\hline $\mathrm{TLC}$, mean $\pm \mathrm{SD} \mathrm{L}$ & $6.6 \pm 1.6$ & $6.6 \pm 1.6$ & $6.4 \pm 1.5$ & 60 & .73 \\
\hline $\mathrm{TLC}$, mean $\pm \mathrm{SD} \%$ & $111.3 \pm 21.0$ & $110 \pm 23$ & $114 \pm 16$ & 64 & .43 \\
\hline $\mathrm{RV}$, mean $\pm \mathrm{SD} \mathrm{L}$ & $4.3 \pm 1.3$ & $4.3 \pm 1.4$ & $4.2 \pm 0.8$ & 62 & .95 \\
\hline $\mathrm{RV}$, mean $\pm \mathrm{SD} \%$ & $180.5 \pm 51.9$ & $178 \pm 60$ & $184 \pm 27$ & 68 & .56 \\
\hline $\mathrm{D}_{\mathrm{LCO}}$, mean $\pm \mathrm{SD} \%$ & $45.6 \pm 21.4$ & $46 \pm 21$ & $46 \pm 24$ & 57 & $>.99$ \\
\hline $\mathrm{K}_{\mathrm{CO}}$, mean $\pm \mathrm{SD} \%$ & $51.7 \pm 22.7$ & $51 \pm 22$ & $55 \pm 27$ & 54 & .55 \\
\hline MMRC, median (interquartile range) & $3.0(2-4)$ & & & & \\
\hline $6 \mathrm{MWD}$, mean $\pm \mathrm{SD} \mathrm{m}$ & $227.7 \pm 91.5$ & $243 \pm 91$ & $198 \pm 87$ & 89 & .03 \\
\hline $\mathrm{S}_{\mathrm{pO}_{2}}(6 \mathrm{MWT})<90 \%, n(\%)$ & $61(65.6)$ & $39(42.4)$ & $21(22.8)$ & 81 & .25 \\
\hline \multicolumn{6}{|c|}{$\begin{array}{l}\mathrm{TLC}=\text { total lung capacity } \\
\mathrm{RV}=\text { residual volume } \\
\mathrm{D}_{\mathrm{LCO}}=\text { lung diffusing capacity determined by the single-breath technique } \\
\mathrm{K}_{\mathrm{CO}}=\text { carbon monoxide transfer coefficient } \\
\mathrm{MMRC}=\text { Modified Medical Research Council dyspnea scale } \\
6 \mathrm{MWD}=6 \text {-min walk distance } \\
6 \mathrm{MWT} \mathrm{S}_{\mathrm{pO}_{2}}<90 \%=6 \text {-min walk test with oxygen saturation }<90 \%\end{array}$} \\
\hline
\end{tabular}

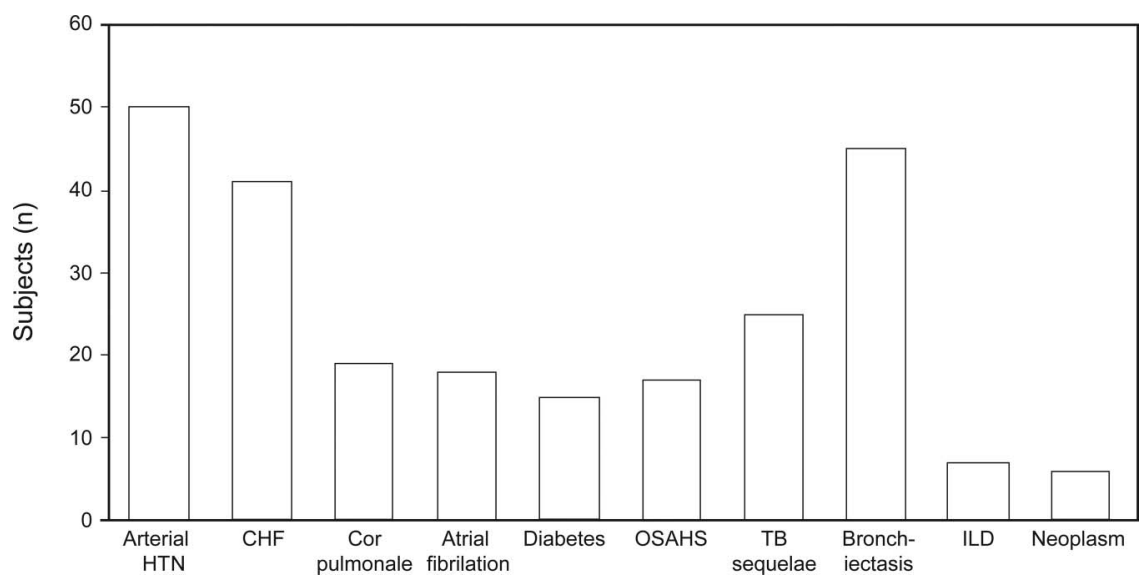

Fig. 1. Comorbidities in subjects with COPD after pulmonary rehabilitation. Arterial HTN = arterial hypertension, CHF $=$ congestive heart failure, OSAHS = obstructive sleep apnea-hypopnea syndrome, TB sequelae = tuberculosis sequelae, ILD = interstitial lung disease.

mortality in subjects with COPD. ${ }^{16,27}$ In fact, 6MWD is a stronger mortality predictor than $\mathrm{FEV}_{1},{ }^{28}$ in part because it is also influenced by other factors: cardiovascular performance, peripheral muscle function, body composition, and other comorbidities. The ECLIPSE study ${ }^{29}$ enrolling a large number of subjects with COPD $(n=2,164)$ evidenced the prognostic value of $6 \mathrm{MWD}$ in mortality. Spruit et al ${ }^{13}$ found that a 6MWD threshold of $334 \mathrm{~m}$ predicted an increased risk of death. In our study, mean 6MWD was lower than this cut-off $(227.7 \mathrm{~m})$. Bowen et $\mathrm{al}^{30}$ have demonstrated that variables strongly associated with increased survival following a pulmonary rehabilitation program included a higher post-rehabilitation functional activities score and higher post-rehabilitation 6MWD. Also, general daily physical activity (eg, standard walking) has proven to be beneficial for these patients, reducing hospital admissions and global mortality. ${ }^{31}$

Pulmonary rehabilitation in all stages of COPD is an effective and important therapy to improve exercise tolerance, muscle strength, and quality of life and decrease respiratory symptoms. Therefore, it should be provided to all symptomatic patients with COPD. It is also fundamental to refer patients with COPD as early as possible (avoiding referral only when patients reach advanced stage disease) in order to improve functional capacity and to further stimulate regular physical activity.

A logistic regression model analysis confirmed that previous hospital admissions was associated with an increased 


\section{Predictive Factors for Mortality in COPD}

death risk (relative risk $1.57, P=.001$ ) in the $3 \mathrm{y}$ after the program.

Exacerbations of COPD are associated with a lower quality of life and are a risk factor for increased mortality ${ }^{11,32}$; therefore, reducing the number of hospitalizations is a priority in the management of these patients. ${ }^{13}$ In our study, there were fewer admissions in the 3-y period following the pulmonary rehabilitation program, yet this did not reach statistical significance $(1.7 \pm 2.2$ versus $2.1 \pm 2.6, P=.17$ ), similar to what happened in other studies. ${ }^{17,18}$ This could be explained by the fact that subjects included in our study had severe air-flow obstruction and therefore had, in general, more hospital admissions. In deceased subjects, the only factor associated with early mortality was atrial fibrillation, although this association was not statistically significant $(P=.050)$.

COPD has been associated with an increased prevalence of lung cancer, osteoporosis, anemia, coronary heart disease, anxiety, and depression. ${ }^{6}$ In fact, COPD is associated with a high prevalence of comorbidities. In a study by Areias et al, ${ }^{33}$ 97\% subjects with GOLD stage IV COPD presented with at least one comorbidity, with an average of 4 comorbidities/subject. In another study from our group, ${ }^{34}$ 114 subjects with COPD who attended a pulmonary rehabilitation program had the same high percentage of comorbidities (96.5\%). Divo et al ${ }^{8}$ evaluated 1,664 subjects for 51 months, recording their comorbidities. They developed a graphic representation system of the prevalence and strength of association with mortality in the form of a "comorbidome." These authors found an average number of comorbidities of 6 , and $58.9 \%$ of subjects had at least one cardiovascular comorbidity. In their study, atrial fibrillation/flutter had a strong association with increased risk for death (HR 1.56, $P=.001$ ). Cardiovascular disease, therefore, plays a fundamental role in mortality of patients with COPD, ${ }^{8,33}$ and our study reflected the higher prevalence of such comorbidities, namely arterial hypertension and congestive heart failure.

Identification and control of risk factors, such as smoking, is a key factor for COPD, lung cancer, and cardiovascular comorbidity management and might have an impact on long-term outcomes, including survival. As demonstrated by Bowen et al, ${ }^{30}$ the 2 functional status indicators, 6MWD and the functional activity subscore, were the strongest predictors of post-rehabilitation survival; therefore, pulmonary rehabilitation and an increase in patients' daily physical activity should be encouraged.

This study's limitations include the retrospective nature of the historical cohort, not allowing for control of all variables in the sample of subjects, and the possible presence of unidentified confounders. Regarding sample size, although we recognize that our cohort size $(n=92)$ is suboptimal to test variables with a weak association with mortality, it is (and in fact was) enough to test variables strongly associated with mortality. Second, the study population is restricted to subjects attending a pulmonary rehabilitation program in a day-hospital for chronic respiratory failure. Therefore, the findings are only applicable to that group of severe subjects, and we cannot generalize our results to all patients with COPD. Also, the referral of subjects to a pulmonary rehabilitation program could result in a referred bias toward subjects with a greater degree of limitations or symptoms. Third, there was a high prevalence of males, so we cannot extend conclusions to the female sex.

\section{Conclusions}

There was a high mortality rate in subjects with latestage COPD who underwent a pulmonary rehabilitation program, the most relevant factors associated with mortality being lung cancer, respiratory failure and noninvasive ventilation, severe exacerbations with hospitalization, and lower functional exercise capacity. Pulmonary rehabilitation program plays a fundamental role by increasing patients' daily physical activity, reducing hospital admissions and global mortality. Also the management of these patients' multiple comorbidities might have an impact on long-term outcomes, including survival.

\section{REFERENCES}

1. World Health Organization. World Health Statistics 2008. Part 1. Ten highlights in health statistics. http://www.who.int/gho/publications/ world_health_statistics/EN_WHS08_Part1.pdf?ua=1. Accessed March 14, 2016.

2. Raherison C, Girodet PO. Epidemiology of COPD. Eur Respir Rev 2009;18(114):213-221.

3. Hoyert DL, Xu J. Deaths: preliminary data for 2011. Natl Vital Stat Rep 2012;61(6):1-51.

4. Global Initiative for Chronic Obstructive Lung Disease. Global strategy for the diagnosis, management, and prevention of chronic obstructive pulmonary disease. Updated 2015. http://www.goldcopd.org/uploads/ users/files/GOLD_Report_2015_Feb18.pdf.

5. Lindberg A, Sawalha S, Hedman L, Larsson LG, Lundbäck B, Rönmark E. Subjects with COPD and productive cough have an increased risk for exacerbations and death. Respir Med 2015;109(1): 88-95.

6. Cavaillès A, Brinchault-Rabin G, Dixmier A, Goupil F, Gut-Gobert C, Marchand-Adam S, et al. Comorbidities of COPD. Eur Respir Rev 2013;22(130):454-475.

7. Mador MJ, Deniz O, Aggarwal A, Kufel TJ. Quadriceps fatigability after single muscle exercise in patients with chronic obstructive pulmonary disease. Am J Respir Crit Care Med 2003;168(1):102-108.

8. Divo M, Cote C, de Torres JP, Casanova C, Marin JM, Pinto-Plata $\mathrm{V}$, et al. Comorbidities and risk of mortality in patients with chronic obstructive pulmonary disease. Am J Respir Crit Care Med 2012; 186(2):155-161.

9. Similowski T, Agustí A, MacNee W, Schönhofer B. The potential impact of anaemia of chronic disease in COPD. Eur Respir J 2006; 27(2):390-396

10. Cote CG. Surrogates of mortality in chronic obstructive pulmonary disease. Am J Med 2006;119(10 Suppl 1):54-62. 


\section{Predictive Factors for Mortality in COPD}

11. Marchetti N, Criner GJ, Albert RK. Preventing acute exacerbations and hospital admissions in COPD. Chest 2013;143(5):1444-1454.

12. Quintana JM, Esteban C, Unzurrunzaga A, Garcia-Gutierrez S, Gonzalez N, Barrio I, et al. Predictive score for mortality in patients with COPD exacerbations attending hospital emergency departments. BMC Med 2014;12:66.

13. Spruit MA, Singh SJ, Garvey C, ZuWallack R, Nici L, Rochester C, et al. An official American Thoracic Society/European Respiratory Society statement: key concepts and advances in pulmonary rehabilitation. Am J Respir Crit Care Med 2013;188(8):e13-e64.

14. McCarthy B, Casey D, Devane D, Murphy K, Murphy E, Lacasse Y. Pulmonary rehabilitation for chronic obstructive pulmonary disease. Cochrane Database Syst Rev 2015;(2):CD003793.

15. Esteban C, Quintana JM, Aburto M, Moraza J, Egurrola M, PérezIzquierdo J, et al. Impact of changes in physical activity on healthrelated quality of life among patients with COPD. Eur Respir J 2010;36(2):292-300.

16. Dajczman E, Wardini R, Kasymjanova G, Préfontaine D, Baltzan MA, Wolkove N. Six minute walk distance is a predictor of survival in patients with chronic obstructive pulmonary disease undergoing pulmonary rehabilitation. Can Respir J 2015;22(4):225-229.

17. Bourbeau J, Julien M, Maltais F, Rouleau M, Beaupré A, Bégin R, et al. Reduction of hospital utilization in patients with chronic obstructive pulmonary disease: a disease-specific self-management intervention. Arch Intern Med 2003;163(5):585-591.

18. Griffiths TL, Phillips CJ, Davies S, Burr ML, Campbell IA. Cost effectiveness of an outpatient multidisciplinary pulmonary rehabilitation programme. Thorax 2001;56(10):779-784.

19. Puhan MA, Scharplatz M, Troosters T, Steurer J. Respiratory rehabilitation after acute exacerbation of COPD may reduce risk for readmission and mortality: a systematic review. Respir Res 2005;6:54.

20. Celli B. Pulmonary Rehabilitation in COPD. UpToDate, last update April 27, 2015. Philadephia: Wolters Kluwer Health Clinical Solutions. www.uptodate.com/contents/pulmonary-rehabilitation-incopd.

21. Celli BR, Cote CG, Marin JM, Casanova C, Montes de Oca M, Mendez RA, et al. The body-mass index, airflow obstruction, dyspnea, and exercise capacity index in chronic obstructive pulmonary disease. N Engl J Med 2004;350(10):1005-1012.

22. ATS Committee on Proficiency Standards for Clinical Pulmonary Function Laboratories. ATS statement: guidelines for the six-minute walk test. Am J Respir Crit Care Med 2002;166(1):111-117.
23. Nishimura K, Izumi T, Tsukino M, Oga T. Dyspnea is a better predictor of 5-year survival than airway obstruction in patients with COPD. Chest 2002;121(5):1434-1440.

24. Martinez FJ, Foster G, Curtis JL, Criner G, Weinmann G, Fishman A, et al. Predictors of mortality in patients with emphysema and severe airflow obstruction. Am J Respir Crit Care Med 2006;173(12): 1326-1334

25. Hjalmarsen A, Brenn T, Jongsma Risberg M, Meisler Antonsen K, Kristiansen Benum E, Aaseboe U. Retrospective survival in elderly COPD patients receiving pulmonary rehabilitation: a study including maintenance rehabilitation. BMC Res Notes 2014;7:210.

26. Burney P, Jithoo A, Kato B, Janson C, Mannino D, NizankowskaMogilnicka E, et al. Chronic obstructive pulmonary disease mortality and prevalence: the associations with smoking and poverty: a BOLD analysis. Thorax 2014;69(5):465-473.

27. Waschki B, Kirsten A, Holz O, Müller KC, Meyer T, Watz H, Magnussen H. Physical activity is the strongest predictor of all-cause mortality in patients with COPD: a prospective cohort study. Chest 2011;140(2):331-342.

28. Garcia-Aymerich J, Lange P, Benet M, Schnohr P, Antó JM. Regular physical activity reduces hospital admission and mortality in chronic obstructive pulmonary disease: a population based cohort study. Tho$\operatorname{rax}$ 2006;61(9):772-778.

29. Vestbo J, Anderson W, Coxson HO, Crim C, Dawber F, Edwards L, et al. Evaluation of COPD longitudinally to identify predictive surrogate end-points (ECLIPSE). Eur Respir J 2008;31(4):869-873.

30. Bowen JB, Votto JJ, Thrall RS, Haggerty MC, Stockdale-Woolley R, Bandyopadhyay T, ZuWallack RL. Functional status and survival following pulmonary rehabilitation. Chest 2000;118(3):697-703.

31. Wouters EF, Franssen FM, Spruit MA. Survival and physical activity in COPD: a giant leap forward! Chest 2011;140(2):279-281.

32. Soler-Cataluña JJ, Martínez-García MA, Sánchez LS, Tordera MP, Sánchez PR. Severe exacerbations and BODE index: two independent risk factors for death in male COPD patients. Respir Med 2009; 103(5):692-699.

33. Areias V, Carreira S, Anciães M, Pinto P, Bárbara C. Co-morbidities in patients with GOLD stage 4 chronic obstructive pulmonary disease. Rev Port Pneumol 2014;20(1):5-11.

34. Carreiro A, Santos J, Rodrigues F. Impact of comorbidities in pulmonary rehabilitation outcomes in patients with chronic obstructive pulmonary disease. Rev Port Pneumol 2013;19(3):106-113. 